\title{
1 Biomechanics of aging and osteoarthritic human knee 2 ligaments
}

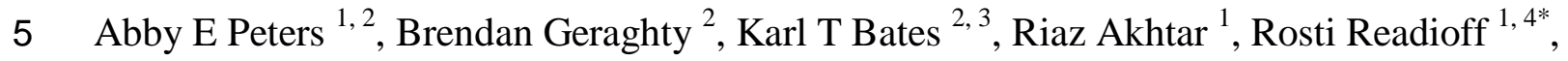
6 Eithne Comerford ${ }^{2,3,5^{*}}$

${ }^{1}$ Department of Mechanical, Materials and Aerospace Engineering, School of Engineering, 9 University of Liverpool, Liverpool, L69 3GH, United Kingdom.

$10{ }^{2}$ Institute of Life Course and Medical Sciences, University of Liverpool, Liverpool, L7 8TX, 11 United Kingdom.

$12{ }^{3}$ Medical Research Council Versus Arthritis Centre for Integrated Research into

13 Musculoskeletal Ageing (CIMA), University of Liverpool, Liverpool, United Kingdom.

$14{ }^{4}$ Institute of Medical and Biological Engineering, School of Mechanical Engineering, Faculty of 15 Engineering, University of Leeds, Leeds, UK.

$16{ }^{5}$ School of Veterinary Science, University of Liverpool, Neston, CH64 7TE, United Kingdom.

Corresponding Authors *:

20 Rosti Readioff 1,4

21 Institute of Medical and Biological Engineering, School of Mechanical Engineering, University

22 of Leeds, Leeds, LS2 9JT, UK

23 Email address: r.readioff@leeds.ac.uk

\section{Eithne Comerford ${ }^{2,3,5}$}

26 Institute of Life Course and Medical Sciences, University of Liverpool, Liverpool, UK.

27 School of Veterinary Science, University of Liverpool, Neston, UK.

28 E-mail address: Eithne.Comerford@liverpool.ac.uk 


\section{Abstract}

31 Background. Ligaments work to stabilize the human knee joint and prevent excessive movement. Whilst ligaments are known to decline in structure and function with aging, there has been no systematic effort to study changes in gross mechanical properties in the four major

34 human knee ligaments due to osteoarthritis (OA). This study aims to collate material properties for the anterior (ACL) and posterior (PCL) cruciate ligaments, medial (MCL) and lateral (LCL) collateral ligaments. Our cadaveric samples come from a diverse demographic from which the effects of aging and OA on bone and cartilage material properties have already been quantified. Therefore, by combining our previous bone and cartilage data with the new ligament data from this study we are facilitating subject-specific whole-joint modelling studies.

Methods. The demographics of the collected cadaveric knee joints were diverse with age range

41 between 31 to 88 years old, and OA International Cartilage Repair Society grade 0 to 4 . Twelve

42 cadaveric human knee joints were dissected, and bone-ligament-bone specimens were extracted

43 for mechanical loading to failure. Ligament material properties were determined from the load-

44 extension curves, namely: linear and ultimate (failure) stress and strain, secant modulus, tangent

45 modulus, and stiffness.

46 Results. There were significant negative correlations between age and ACL linear force

$47(p=0.01)$, stress $(p=0.03)$ and extension $(p=0.05)$, ACL failure force $(p=0.02)$, stress $(p=0.02)$

48 and extension $(p=0.02)$, PCL secant $(p=0.02)$ and tangent $(p=0.02)$ modulus, and LCL stiffness

$49(p=0.05)$. Significant negative correlations were also found between OA grades and ACL linear

50 force $(p=0.05)$, stress $(p=0.02)$, extension $(p=0.01)$ and strain $(p=0.03)$, and LCL failure stress

$51(p=0.05)$. However, changes in age or OA grade did not show a statistically significant

52 correlation with the MCL tensile parameters. Trends showed that almost all the tensile 
53 parameters of the ACL and PCLs decreased with increasing age and progression of OA. Due to

54 small sample size, the combined effect of age and presence of OA could not be statistically

55 derived.

56 Conclusions. This research is the first to correlate changes in tensile properties of the four major

57 human knee ligaments to aging and OA. The current ligament study when combined with our

58 previous findings on bone and cartilage for the same twelve knee cadavers, supports

59 conceptualization of OA as a whole-joint disease that impairs the integrity of many peri-articular

60 tissues within the knee. The subject-specific data pool consisting of the material properties of the

61 four major knee ligaments, subchondral and trabecular bones and articular cartilage will aid

62 reconstruction and graft replacements and advance knee joint finite element models, whilst

63 knowledge of aged or diseased mechanics may direct future therapeutic interventions. 


\section{Introduction}

66 The human knee joint is composed of both soft and hard tissues, forming a diarthrosis

67 articulation between the femur and tibia, allowing predominantly flexion and extension in the

68 sagittal plane (Nigg \& Herzog, 2007). Primary human knee joint ligaments act as strain sensors,

69 constraining degrees of freedom to provide stabilization and prevent excessive movement

70 (Harner et al., 1995; Woo et al., 2006). Structurally, ligaments have direct and indirect insertions

71 into the bone and periosteum (Woo et al., 2006) allowing fiber bundle variations to respond to

72 different movements and resist loading during tension or rotation at the joint (Hansen, Masouros

$73 \&$ Amis, 2006).

75 Tensile properties of the anterior cruciate ligament (ACL), posterior cruciate ligament (PCL),

76 medial collateral ligament (MCL) and lateral collateral ligament (LCL) have been explored by

77 numerous researchers (Noyes \& Grood, 1976; Woo et al., 1991; Race \& Amis, 1994; Robinson,

78 Bull \& Amis, 2005; Bonner et al., 2015; Smeets et al., 2017; Cho \& Kwak, 2020; Patel et al.,

79 2021), providing important information on their structural and mechanical properties. Data for all

80 four ligaments exists across various sources in the literature; however, these are most often

81 harvested and tested in isolation, obtaining just one ligament type from donors. To date, very few

82 studies have explored all four ligaments from the same donor (donors were limited to healthy

83 knee joints), with data suggesting higher stiffness and failure load in the cruciate ligaments

84 compared to the collateral ligaments (Trent, Walker \& Wolf, 1976; van Dommelen et al., 2005).

85 Despite data existing for all four ligaments from varying specimens in previous studies, there is

86 marked variability in reported values, likely due to variations in testing techniques and donor 
87 demographics, which currently makes it challenging to understand whole-joint function (Peters

88 et al., 2018a) .

90 The lack of consistent healthy baseline measurements means our understanding of how tensile

91 properties of all four ligaments within the same knee joint change with aging or disease is

92 presently unclear (Peters et al., 2018a). Structural and functional capabilities are known to

93 decline with age in the ACL, in particular a decrease in ultimate failure load from older donors

94 (67 to 90 years), when compared to donors between 40 to 50 years old, and younger donors (22

95 to 35 years) (Woo et al., 1991). This is also reflected at a cellular level in ligaments such that

96 ACL histological parameters, including cartilage fiber disorganization and mucoid degeneration,

97 showed an increase in tissue degeneration with age (Hasegawa et al., 2012). However, any

98 differences in material properties in the PCL, MCL and LCL are yet to be systematically

99 correlated with different age categories. Changes to integrity and tensile properties not only leave

100 ligaments vulnerable to further injury but also affect the peri-articular tissues leading to muscle

101 weakening through immobility, and whole-joint disruption including the development of

102 osteoarthritis (OA) (Rousseau \& Garnero, 2012; Manninen et al., 1996; Simon et al., 2015). In

103 addition, our knowledge about the effect of OA on the tensile properties of the knee joint

104 ligaments is limited, with current studies focusing primarily on histological analyses. There is

105 evidence showing impaired integrity of the ACL and PCL during total knee replacements in the

106 presence of OA and with age (Mullaji et al., 2008; Hasegawa et al., 2012).

107

108 It is valuable to link the previously observed data on histological and micro-scale morphological

109 changes due to aging and OA in the knee joint ligaments, to changes in the tissue-level ligament 
mechanics, and then to the whole knee joint mechanics (Kumar, Manal \& Rudolph, 2013;

111 Adouni, Shirazi-Adl \& Shirazi, 2012). Previously, we systematically investigated the effect of

112 age and OA on the mechanical properties of bone and cartilage in human knee joints for the first

113 time on the same donor (Peters et al., 2018b). Here, we have employed the same human cadavers

114 to study the ligaments. This therefore will allow (i) the first assessment of changes in the

115 mechanical behavior of ligaments due to aging and OA, (ii) ligament data to be combined with

116 bone and cartilage trends from the same specimen to give a fuller picture of multi-tissue joint

117 (whole-joint) changes with age and OA, and (iii) the subject-level data to be used in future

118 development of subject-specific OA knee joint computer models. Thus, the aim of this study was

119 to obtain data on tissue-level material characteristics of cadaveric human knee joint ligaments

120 with a wide span of age and OA grades and correlate these to age and OA grade as univariate

121 parameters. To fulfill the aim of this study, the following objectives were performed:

122 1. Harvesting the four major knee joint ligaments (ACL, PCL, LCL and MCL) as a bone-

123 ligament-bone specimens, and measure undeformed geometrical parameters of the

$124 \quad$ ligaments.

125 2. Application of physiologically relevant tensile loads on the ligaments and determining 126 their mechanical responses.

127 3. Analysis of the tensile characteristics of the ligaments and tests of their correlations with $128 \quad$ age and OA. 
132 Fresh-frozen human cadaveric knee joints were sourced from Science Care (Phoenix, Arizona,

133 United States) via Newcastle Surgical Training Centre (Newcastle upon Tyne, NE7 7DN, United

134 Kingdom); therefore, the consents were obtained and held by Science Care. The knee cadavers

135 were from humans aged 31 to 88 years $(n=12 ; 4$ female and 8 male) (Table S2) as reported in

136 our previous study (Peters et al., 2018b). Ethical permission for use of this human cadaveric

137 material was sponsored by the University of Liverpool and granted by the National Research

138 Ethics Service (15/NS/0053) who approved all protocols. All experiments were performed in

139 accordance with relevant guidelines and regulations.

140

141 Cadaver limbs were initially frozen at $-20^{\circ} \mathrm{C}$ and thawed at 3 to $5^{\circ} \mathrm{C}$ for 5 days prior to

142 dissection. During dissection, cadavers were photographed and graded for OA using the

143 International Cartilage Repair Society (ICRS) (Supplementary Materials (Table S1)) as reported

144 in our previous study (Peters et al., 2018b). Four bone-ligament-bone specimens were harvested

145 from each cadaver using a low-speed oscillating saw (deSoutter Medical, Bucks, UK) (Fig. 1A).

146 Extracted specimens were then stored at $-20^{\circ} \mathrm{C}$ before they were thawed for 24 hours at 3 to $5^{\circ} \mathrm{C}$

147 and submerged in phosphate buffered saline (PBS). Overall the specimens underwent two freeze-

148 thaw cycles, which has previously been shown to have no effect on ligament and tendon material

149 properties (Woo et al., 1986; Moon et al., 2006; Huang et al., 2011; Jung et al., 2011; Peters et

150 al., 2017). Specimen numbers are consistent with those in Peters et al. (2018b), allowing

151 matching of ligament properties presented here with previously reported cartilage and bone data

152 from the same individuals (Supplementary Materials (Ligament Raw Data.xlsx)). 
155 The cross-sectional area of all of the ligament specimens were obtained using a previously

156 described method (Goodship \& Birch, 2005; Readioff et al., 2020b). In brief, using a fast-setting

157 alginate impression paste (UnoDent, Essex, England) ligaments were encased in the material and

158 left to set for two minutes (Fig. 1B). Once the impression material was set, a scalpel blade was

159 used to slice the mold which was then filled with polymethyl-methacrylate (PMMA) (Teknovit

160 6091, Heraeus Kulzer GmbH, Wehrheim, Germany) to create a replica of the ligament structure.

161 Once the PMMA was set, the mold was sliced transversely, and the resulting ends colored with

162 permanent white marker pen (Fig. 1C). The cement mold ends were then photographed and

163 digitally measured using ImageJ (Schneider, Rasband \& Eliceiri, 2012) to obtain the cross-

164 sectional area of the ligament.

Specimen Preparation

167 Bone around the insertion and origin sites of each ligament on the femur and tibia were cut into a

168 suitable shape using a hand saw (Fig. 1A). The bone ends of the specimens were potted into

169 custom-made stainless-steel holders and screwed in place. PMMA was then poured into the

170 holder and left to cure for 4 to 5 minutes. Specimens were then attached to the load cell and

171 encased into a watertight custom-made chamber. The chamber was filled with PBS to control

172 specimen hydration during testing (Fig. 2).

\section{Tensile Testing Protocol}

175 Using a uniaxial tensile testing machine (Instron 3366, Buckinghamshire, UK) with a $5000 \mathrm{~N}$

176 load cell (Instron 2519), a 1 N preload was applied and all ligaments underwent ten

177 preconditioning cycles at $10 \mathrm{~mm} / \mathrm{min}$ with a load of 1 to $40 \mathrm{~N}$, which provides a stable and 
178 repeatable viscoelastic response (Momersteeg et al., 1995). Loading was then set to zero and

179 ligaments were loaded to failure at $500 \mathrm{~mm} / \mathrm{min}$. A fast strain rate was chosen over slow stain

180 rates to mimic physiological loading (Noyes \& Grood, 1976; Sharma et al., 2008; Bersini,

181 Sansone \& Frigo, 2016) and replicate a realistic injury environment (Robinson, Bull \& Amis,

182 2005). In addition, faster strain rates improve the chances of the ligament rupturing mid-

183 substance as opposed to a bony avulsion (Noyes \& Grood, 1976).

\section{Material Properties}

186 The bone-ligament-bone specimens were mechanically tested and analyzed to collate multiple

187 material property data (Fig. 3). Linear parameters were calculated from the last data point on the

188 linear slope of the curve, whereas failure parameters were calculated from the attained maximum

189 load, the parameters were force, elongation, stress, strain, secant modulus, tangent modulus (the

190 slope between maximum and sub-maximum points of the linear region of the load-extension

191 curve) and stiffness (Fig. 3).

$\sigma_{\text {max linear }}=\frac{F_{\text {max linear }}}{C S A}$

$\sigma_{\text {failure }}=\frac{F_{\text {failure }}}{C S A}$

192 where $\sigma_{\text {max linear }}$ and $\sigma_{\text {failure }}$ are stresses $(\mathrm{MPa})$ at the maximum linear and failure points,

$193 F_{\text {max linear }}$ and $F_{\text {failure }}$ are forces $(\mathrm{N})$ at the maximum linear and failure points, and CSA is

194 cross-sectional area $\left(\mathrm{mm}^{2}\right)$. 


$$
\begin{aligned}
& \varepsilon_{\text {max linear }}=\frac{L_{\text {max linear }}-L_{0}}{L_{0}} \\
& \varepsilon_{\text {failure }}=\frac{L_{\text {failure }}-L_{0}}{L_{0}}
\end{aligned}
$$

195 where $\varepsilon_{\text {max linear }}$ and $\varepsilon_{\text {failure }}$ are strains $(\%)$ at the maximum linear and failure points,

$196 L_{\text {max linear }}$ and $L_{\text {failure }}$ are lengths $(\mathrm{mm})$ at the maximum linear and failure points, and $L_{0}$ is

197 original length (mm) of the ligament.

$$
\begin{aligned}
& E_{\text {secant }}=\frac{\sigma_{\text {max linear }}}{\varepsilon_{\text {max linear }}} \\
& E_{\text {tan }}=\frac{\sigma_{\text {failure }}}{\varepsilon_{\text {failure }}} \\
& k=\frac{E_{\text {secant }} \times C S A}{L_{0}}
\end{aligned}
$$

198 where $E_{\text {secant }}$ is secant modulus $(\mathrm{MPa}), E_{\text {tan }}$ is tangent modulus (MPa) at the maximum linear 199 region of the load-extension curve, and $k$ is ligament stiffness $(\mathrm{N} / \mathrm{mm})$.

202 Kruskal-Wallis one-way ANOVA was conducted to compare mean differences of ligament

203 material properties between young healthy ( $\leq 60$ years old, ICRS grade 0 ), young OA ( $\leq 60$ years

204 old, ICRS grade 1-4) and old OA (>60, ICRS grade 1-4) cohorts. Ligament tensile properties

205 were correlated with increasing age and grade of OA using a Kendall's Tau-b $\left(\tau_{b}\right)$ correlation

206 coefficient. The material properties included in the analyses were: linear force, linear stress, 
207 linear strain, failure load, failure stress, failure strain, secant modulus, tangent modulus, and

208 stiffness. Both of the statistical analyses were performed in SPSS (SPSS software, Version 22.0,

209 SPSS, Inc., Chicago, IL).

210

211 Results

212 Specimens

213 ACL $(n=12)$, PCL $(n=12)$, MCL $(n=12)$, and LCL $(n=12)$ specimens were obtained from

214 twelve human cadavers. One MCL specimen from a young (37 years old) healthy donor was

215 visually determined as severely abnormal and data from two MCL specimens from ICRS grade 1

216 donors were unable to be retained (Supplementary Materials (Fig. S1)). Hence, they were

217 excluded from statistical analyses.

218

219 The ICRS grading for all 12 cadaveric knees were given and reported in Table 1 which is the 220 same as those reported in our previous work (Peters et al., 2018b). Three knees were given ICRS

221 grade 0 (age: 31, 37 and 43 years old), another three knees with ICRS grade 1 (age: 49, 51 and

22286 years old), two knees with ICRS grade 2 (age: 58 and 79 years old), three knees with ICRS

223 grade 3 (age: two 72 and 88 years old) and one knee with ICRS grade 4 (age: 80 years old).

225 Cross-Sectional Area \& Length Measurements

226 The cross-sectional areas of the ACLs, PCLs, LCLs and MCLs were in the range of 24.98 to

$227101.84,48.82$ to $154.25,12.83$ to 71.75 , and 18.19 to $58.68 \mathrm{~mm}^{2}$, respectively. The length of the

228 ACLs, PCLs, LCLs and MCLs were in the range of 28 to 41, 30 to 46, 47 to 74, and 40 to 127 
mm, respectively. The cross-sectional areas and lengths of individual ligaments for each donor

230 are reported in Table 1.

Correlation with Age

233 Increasing age resulted in statistically significant negative correlations with ACL linear force $\left(\tau_{b}\right.$

$234=-0.63, p=0.01)$, linear stress $\left(\tau_{b}=-0.47, p=0.03\right)$, linear extension $\left(\tau_{b}=-0.44, p=0.05\right)$,

235 failure force $\left(\tau_{b}=-0.50, p=0.02\right)$ and failure stress $\left(\tau_{b}=-0.53, p=0.02\right)$ (Fig. 4). No

236 statistically significant correlation was found between age and ACL linear strain, secant and

237 tangent modulus, failure strain and stiffness (Supplementary Materials (Table S4 and

238 ACL_AllStat.xls)).

240 Increasing age showed statistically significant negative correlations with PCL secant modulus

$241\left(\tau_{b}=-0.50, p=0.02\right)$ and tangent modulus $\left(\tau_{b}=-0.53, p=0.02\right)$. No statistically significant

242 correlations were found between age and the rest of the PCL tensile parameters (Supplementary

243 Materials (Table S4 and PCL_AllStat.xls)).

245 There were no statistically significant correlations between age and MCL tensile parameters

246 (Supplementary Materials (MCL_AllStat.xls)). Only LCL stiffness showed statistically

247 significant negative correlation with age $\left(\tau_{b}=-0.44, p=0.05\right)$ and no additional significant

248 correlations were found for the LCL tensile properties (Supplementary Materials (Table S4 and 
251 Detailed correlation of age with material properties of the four ligaments are reported in the

252 Supplementary Materials (Table S3, Table S4 and Fig. S3).

\section{Correlation with Osteoarthritis}

255 Increasing OA grade showed statistically significant negative correlation with ACL linear force

$256\left(\tau_{b}=-0.46, p=0.05\right)$, linear stress $\left(\tau_{b}=-0.53, p=0.02\right)$, linear extension $\left(\tau_{b}=-0.59, p=0.01\right)$

257 and linear strain $\left(\tau_{b}=-0.5, p=0.03\right)$. However, the correlations between OA and the rest of the

258 ACL tensile parameters were not statistically significant (Supplementary Materials (Table S4

259 and ACL_AllStat.xls)).

261 There were no statistically significant correlations between OA grade and PCL and MCL tensile

262 parameters. Only LCL failure stress showed statistically significant negative correlation between

263 OA grade and LCL failure stress $\left(\tau_{b}=-0.46, p=0.05\right)$ and the rest of the LCL tensile

264 parameters were not statistically significant (Supplementary Materials (PCL_AllStat.xls,

265 MCL_AllStat.xls, and LCL_AllStat.xls)).

267 Detailed correlation of OA with material properties of the four ligaments are reported in the

268 Supplementary Materials (Table S3, Table S4 and Fig. S3).

\section{Discussion}

271 This is the first ex vivo study to quantify of the effects of aging and OA on the material

272 properties of the four primary knee ligaments from the same cadaveric joints within a wide span

273 of age (31 to 88 years old) and OA grade (ICRS 0 to 4). Our results showed statistically 
274 significant negative correlations with ACL linear and failure forces, stresses and extensions, PCL

275 secant and tangent modulus and LCL stiffness (Supplementary Materials (Table S4)). Similarly,

276 increasing OA grade resulted in statistically significant negative correlation with ACL linear

277 forces, stresses, extension, and strains and LCL failure stress (Supplementary Materials (Table

278 S4)). Change in age or OA grade did not have a significant correlation with the MCL material

279 parameters (Supplementary Materials (Table S4)). This data is vital for understanding joint

280 mechanics and it can provide an insight into the progression of OA as a whole-joint disease as

281 well as the effects of aging, notably because bone and cartilage mechanical properties for these

282 specific human cadavers have already been reported in our previous study (Peters et al., 2018b).

284 Failure loads previously reported across any age category span two orders of magnitude between 285495 to $2160 \mathrm{~N}$ in the ACL, 258 to $1620 \mathrm{~N}$ in the PCL, 194 to $534 \mathrm{~N}$ in the MCL and $376 \mathrm{~N}$ in the

286 LCL (Noyes \& Grood, 1976; Trent, Walker \& Wolf, 1976; Woo et al., 1991; Race \& Amis,

287 1994; Harner et al., 1995; Chandrashekar et al., 2006). Furthermore, previous studies also

288 reported stiffness values which ranged between 124 to $308 \mathrm{~N} / \mathrm{mm}$ in the ACL, 57 to $347 \mathrm{~N} / \mathrm{mm}$

289 in the PCL, $70 \mathrm{~N} / \mathrm{mm}$ in the MCL and $59 \mathrm{~N} / \mathrm{mm}$ in the LCL, where values reported for failure

290 load and stiffness in the current study fall within the previously reported range (Noyes \& Grood,

291 1976; Trent, Walker \& Wolf, 1976; Woo et al., 1991; Race \& Amis, 1994; Harner et al., 1995;

292 Chandrashekar et al., 2006). Previous research has indicated a decrease in the ACL failure load

293 with increasing age, which is consistent with the current study (Fig. 4D). Age based differences

294 show ACL failure loads of up to $2160 \mathrm{~N}$ amongst younger donors (22 to 35 years), $1503 \mathrm{~N}$ in

295 middle-aged donors (40 to 50 years) and $658 \mathrm{~N}$ amongst older donors (60 to 97 years), although

296 degeneration of joint integrity was not indicated (Woo et al., 1991). 
298 The current research showed a decrease in the failure strain of all four knee ligaments with the 299 development of OA (Fig. 5E and Supplementary Materials (Fig. S3)). The ACL in healthy knees

300 showed higher linear and failure stresses and strains, secant and tangent modulus and stiffness

301 when compared to those with OA (Fig. 5). The influence of OA has previously been investigated

302 in animal models and a reduction in tensile properties of the rat ACL was reported, ten weeks

303 after collagen-induced arthritis. Ultimate failure load reduced by $25.1 \%$ and stiffness by $38.0 \%$

304 when compared to controls (Nawata et al., 2001). Despite a lack of knee joint material properties

305 in the literature associated to OA in humans, previous research has found that between 39 to $78 \%$

306 of patients with OA have a degenerated ACL (Allain, Goutallier \& Voisin, 2001; Cushner et al.,

307 2003; Lee et al., 2005; Mullaji et al., 2008; Watanabe et al., 2011), and between 7 to 80\% have a

308 degenerated PCL (Nelissen \& Hogendoorn, 2001; Stubbs et al., 2005; Mullaji et al., 2008). Such

309 degeneration is consistent with the decrease in the tensile properties of the four knee joint

310 ligaments observed in our current study.

312 Currently, it is challenging to separate the effects of OA and aging as they often happen

313 concurrently. With only 12 cadavers and five groups of ICRS grades ( 0 to 4$)$, it was challenging

314 to statistically attribute changes in ligament tensile properties to both age and OA as related

315 parameters, particularly when also accounting for sex (see further discussion below). This is a

316 limiting factor of the current study; however, to understand the effect of age and OA as

317 individual parameters, trends were analyzed from the data presented in Table 1 . The trends

318 suggest that in younger donors the ACL and PCL material properties were reduced in the OA

319 knees compared to those in the healthy knees (Supplementary Materials (Fig. S4)). This suggests 
that even mild OA in younger donors affects the material properties which is further exacerbated

321 with advancing age and OA.

323 It is currently unknown whether ligament injury initiates the early-onset of OA, or whether OA is

324 indeed a whole-joint disease impairing the integrity of associated tissues including ligaments

325 (Poole, 2012). In our previous study on the same human cadaveric knees, we found statistically

326 significant correlations between changes in material properties of cartilage and subchondral bone

327 with age and OA grade (Peters et al., 2018b). Similarly, the data in the current study for the same

328 cadavers showed alterations of ligament tensile properties because of OA. It is possible that

329 ligament degeneration or injury occurs in the first instance and this can subsequently lead to the

330 initiation and progression of knee OA (Gianotti et al., 2009). Since the primary function of knee

331 ligaments is to provide stability to the knee joint (Harner et al., 1995; Woo et al., 2006), any

332 changes to the ligaments' structure can alter the load distribution in the knee joint (Moore \&

333 Burris, 2015). The knee cadavers in this study showed that OA degeneration affected the medial

334 more than the lateral compartments of the bones (Peters et al., 2018b). The difference in

335 degeneration between the lateral and medial compartments of the knee joint could be a result of

336 unbalanced load distribution that was caused by changes in the ligament material properties

337 because of OA. Our data also showed that PCL tensile properties most commonly decreased

338 between younger donors with the presence of OA and older donors with the presence of OA

339 (Supplementary Materials (Fig. S4)). This suggests that changes to this ligament are more

340 evident with advanced aging. The reduction in the measured tensile parameters of the ACL

341 during aging and disease progression may be attributed to the relatively high forces experienced

342 during walking. Studies show a consensus that peak force experienced by the ACL occurs at 
343 contralateral toe off during the stance phase of the gait cycle, up to 3.5 times body weight

344 (Morrison, 1970; Collins \& O’Connor, 1991; Shelburne et al., 2004). In particular, these high

345 ACL kinematic forces may be consistent with the widely reported histological degeneration of

346 the ACL in the presence of disease (Mullaji et al., 2008), suggesting high habitual forces could

347 influence subsequent degeneration observed. Peak force of the PCL has also been reported up to

$348 \quad 0.2$ to 0.6 times body weight during walking (Morrison, 1970; Collins \& O’Connor, 1991). There

349 is evidence showing that appropriate exercise training strengthens ligaments and knee joint

350 mechanics (Tipton et al., 1975; Salem et al., 2000; Ng, 2002; Ferri et al., 2003). However, people

351 exercise less as they age hence increasing their risk of ligament degeneration (Daley \& Spinks,

352 2000). Decreased capacity of the knee ligaments to resist motion due to reduced mechanical

353 strength may alter contact forces of the joint, potentially causing increased loading on the medial

354 femoral condyle and contributing to the preferential medial development of OA (Pelletier et al.,

355 2007; Lohmander et al., 2007).

357 Further limitations of the current study, aside from a low sample number, include varying donor

358 demographics, such as sex, which is known to affect tensile properties and likelihood of knee

359 ligament injury. It was found that ACLs in young human females had $22.49 \%$ lower Young's

360 modulus, and $8.3 \%$ and $14.3 \%$ lower failure strain and stress respectively, when compared to

361 ACLs in young human males (Chandrashekar et al., 2006). These differences can be partially

362 attributed to the physically smaller size of the female ACL, which can in turn be linked to higher

363 rates of ACL injuries in female athletes (Anderson et al., 2001; Chandrashekar, Slauterbeck \&

364 Hashemi, 2005). Females are also known to be at a greater risk of knee OA than males (Hame \& 
Alexander, 2013). Again, due to low sample numbers, this study was unable to separate ligaments by sex for statistical analyses.

368 Finally, the current study may be limited by testing ligaments as whole bone-ligament-bone 369 specimens along their loading axis. It has previously been acknowledged that ligaments may be

370 best divided into their fiber bundles in order to recruit fibers to their maximal potential and

371 eliminate any slack due to orientation (Woo et al., 1991; Race \& Amis, 1994). Significant

372 differences have been reported between the anterior and posterior fibers of the ACL (Butler et

373 al., 1992) and PCL (Race \& Amis, 1994; Harner et al., 1995) suggesting that fibers play different

374 roles in the stabilization of the knee joint (Race \& Amis, 1994); although ligaments naturally

375 work as one functional unit. Such global approaches have previously been used in the

376 representation of ligaments in finite element models as one functional unit (Readioff et al.,

377 2020a). However, due to the lack of data on all four ligaments from the same donor (and in 378 certain cases the same demographic or disease conditions of donor) in the literature, material

379 properties have often been applied globally in finite element models, where values for one

380 ligament are replicated for all others (Blankevoort \& Huiskes, 1991; Li, Lopez \& Rubash, 2001;

381 Wang, Fan \& Zhang, 2014; Kazemi \& Li, 2014). In some instances, tendon material properties

382 have been used (Kazemi et al., 2011; Wang, Fan \& Zhang, 2014; Kazemi \& Li, 2014).

383 Sensitivity analysis showed that varying intrinsic ligament material properties alters the internal

384 and external rotation of the tibia-femoral joint, patella tilt and peak contact stress (Dhaher, Kwon

$385 \&$ Barry, 2010). As such, the data in this study combined with cartilage and bone data in our

386 previous study (Peters et al., 2018b) allows future research to apply a subject- or cohort-specific 
approach to computational modelling of the human knee joint to improve accuracy and predictive behavior patterns of ligaments. donors can be used to replicate ligaments by developing more biologically representative synthetic materials for the repair and replacement following injury or degeneration (Yang, Rothrauff \& Tuan, 2013; Ratcliffe et al., 2015). The data collected in this study, therefore,

394 provides insight into not only the healthy range for these parameters but also how they change 395 concurrently with surrounding ligaments during aging and disease.

\section{Conclusions}

398 This research is the first to correlate alterations in tensile properties of the four major human

399 knee ligaments to aging and OA. We confirmed the findings of previous research that the ACL

400 tensile properties decrease with age and OA. The results also provided new evidence that the

401 PCL tangent and secant modulus decrease with increasing age. Although not statistically proven,

402 the MCL and LCL showed some changes with increasing age and OA grade, which has not

403 previously been demonstrated. These data, along with our previously reported data on bone and

404 cartilage material properties for the same cadavers supports current research stating that OA is a

405 whole-joint disease impairing many peri-articular tissues within the knee. The material properties

406 for the four major knee ligaments in the twelve cadavers can be combined with their

407 corresponding subchondral and trabecular bones and articular cartilage for future subject-specific

408 applications including the development of computational models and OA diagnostics. 


\section{Acknowledgements}

411 This project was funded by BBSRC (Research Grant: BB/J014516/1) and the School of

412 Engineering, University of Liverpool.

413 The authors would like to thank Mr Phil Jackson and the staff at the Newcastle Surgical Training

414 Centre, who supported obtainment of cadaveric specimens, and Mr Lee Moore and the staff at

415 the Veterinary Training Suite, Institute of Veterinary Science, University of Liverpool, for the

416 use of surgical tools. We also thank Prof. Ahmed Elsheikh for providing access to the

417 experimental facilities at the School of Engineering, University of Liverpool.

\section{References}

Adouni M, Shirazi-Adl A, Shirazi R. 2012. Computational biodynamics of human knee joint in gait: from muscle forces to cartilage stresses. Journal of Biomechanics 45:2149-2156. DOI: 10.1016/j.jbiomech.2012.05.040.

Allain J, Goutallier D, Voisin MC. 2001. Macroscopic and histological assessments of the cruciate ligaments in arthrosis of the knee. Acta Orthop Scand 72:266-269. DOI:

Anderson AF, Dome DC, Gautam S, Awh MH, Rennirt GW. 2001. Correlation of anthropometric measurements, strength, anterior cruciate ligament size, and intercondylar notch characteristics to sex differences in anterior cruciate ligament tear rates. The American Journal of Sports Medicine 29:58-66. DOI: 10.1177/03635465010290011501.

Bersini S, Sansone V, Frigo CA. 2016. A dynamic multibody model of the physiological knee to predict internal loads during movement in gravitational field. Computer Methods in 
434 Blankevoort L, Huiskes R. 1991. Ligament-bone interaction in a three-dimensional model of the knee. Journal of Biomechanical Engineering 113:263-269. DOI: 10.1115/1.2894883.

Bonner TJ, Newell N, Karunaratne A, Pullen AD, Amis AA, A MJB, Masouros SD. 2015. Strainrate sensitivity of the lateral collateral ligament of the knee. Journal of the Mechanical Behavior of Biomedical Materials 41:261-270.

Butler DL, Guan Y, Kay MD, Cummings JF, Feder SM, Levy MS. 1992. Location-dependent

Chandrashekar N, Mansouri H, Slauterbeck J, Hashemi J. 2006. Sex-based differences in the tensile properties of the human anterior cruciate ligament. Journal of Biomechanics 39:2943-2950. DOI: 10.1016/j.jbiomech.2005.10.031. variations in the material properties of the anterior cruciate ligament. Journal of Biomechanics 25:511-518. DOI: 10.1016/0021-9290(92)90091-E.

Cho H-J, Kwak D-S. 2020. Mechanical Properties and Characteristics of the Anterolateral and Collateral Ligaments of the Knee. Applied Sciences 10:6266. DOI:

Chandrashekar N, Slauterbeck J, Hashemi J. 2005. Sex-based differences in the anthropometric characteristics of the anterior cruciate ligament and its relation to intercondylar notch geometry: a cadaveric study. The American Journal of Sports 10.3390/app10186266.

Collins JJ, O'Connor JJ. 1991. Muscle-ligament interactions at the knee during walking. Proceedings of the Institution of Mechanical Engineers. Part $\mathrm{H}$, Journal of Engineering in Medicine 205:11-18. DOI: 10.1243/PIME_PROC_1991_205_256_02. histologic comparison: ACL degeneration in the osteoarthritic knee. The Journal of Arthroplasty 18:687-692. DOI: 10.1016/s0883-5403(03)00256-0.

Daley MJ, Spinks WL. 2000. Exercise, Mobility and Aging. Sports Medicine 29:1-12. DOI: $10.2165 / 00007256-200029010-00001$ 
Dhaher YY, Kwon T-H, Barry M. 2010. The effect of connective tissue material uncertainties on knee joint mechanics under isolated loading conditions. Journal of Biomechanics

van Dommelen JAW, Ivarsson BJ, Jolandan MM, Millington SA, Raut M, Kerrigan JR, Crandall JR, Diduch DR. 2005. Characterization of the Rate-Dependent Mechanical Properties and Failure of Human Knee Ligaments. SAE Transactions 114:80-90.

Ferri A, Scaglioni G, Pousson M, Capodaglio P, Van Hoecke J, Narici MV. 2003. Strength and

Gianotti SM, Marshall SW, Hume PA, Bunt L. 2009. Incidence of anterior cruciate ligament injury and other knee ligament injuries: A national population-based study. Journal of

Goodship AE, Birch HL. 2005. Cross sectional area measurement of tendon and ligament in vitro: a simple, rapid, non-destructive technique. Journal of Biomechanics 38:605-608. DOI: 10.1016/j.jbiomech.2004.05.003.

Hame SL, Alexander RA. 2013. Knee osteoarthritis in women. Current Reviews in Musculoskeletal Medicine 6:182-187. DOI: 10.1007/s12178-013-9164-0.

478 Hansen U, Masouros S, Amis AA. 2006. (iii) Material properties of biological tissues related to joint surgery. Current Orthopaedics 20:16-22. DOI: 10.1016/j.cuor.2005.12.001.

480 Harner CD, Xerogeanes JW, Livesay GA, Carlin GJ, Smith BA, Kusayama T, Kashiwaguchi S, Woo SL. 1995. The human posterior cruciate ligament complex: an interdisciplinary study. Ligament morphology and biomechanical evaluation. The American Journal of Sports Medicine 23:736-745. DOI: 10.1177/036354659502300617. 
484 Hasegawa A, Otsuki S, Pauli C, Miyaki S, Patil S, Steklov N, Kinoshita M, Koziol J, D’Lima DD, Lotz MK. 2012. Anterior cruciate ligament changes in the human knee joint in aging and osteoarthritis. Arthritis and Rheumatism 64:696-704. DOI: 10.1002/art.33417.

Huang H, Zhang J, Sun K, Zhang X, Tian S. 2011. Effects of repetitive multiple freeze-thaw cycles on the biomechanical properties of human flexor digitorum superficialis and flexor pollicis longus tendons. Clinical Biomechanics (Bristol, Avon) 26:419-423. DOI: 10.1016/j.clinbiomech.2010.12.006.

Jung H-J, Vangipuram G, Fisher MB, Yang G, Hsu S, Bianchi J, Ronholdt C, Woo SL-Y. 2011. The effects of multiple freeze-thaw cycles on the biomechanical properties of the human bone-patellar tendon-bone allograft. Journal of Orthopaedic Research: Official Publication of the Orthopaedic Research Society 29:1193-1198. DOI:

Kazemi M, Li LP. 2014. A viscoelastic poromechanical model of the knee joint in large compression. Medical Engineering \& Physics 36:998-1006. DOI: 10.1016/j.medengphy.2014.04.004.

Kazemi M, Li LP, Savard P, Buschmann MD. 2011. Creep behavior of the intact and meniscectomy knee joints. Journal of the Mechanical Behavior of Biomedical Materials

Kumar D, Manal KT, Rudolph KS. 2013. Knee joint loading during gait in healthy controls and individuals with knee osteoarthritis. Osteoarthritis and Cartilage 21:298-305. DOI:

Lee G-C, Cushner FD, Vigoritta V, Scuderi GR, Insall JN, Scott WN. 2005. Evaluation of the anterior cruciate ligament integrity and degenerative arthritic patterns in patients undergoing total knee arthroplasty. The Journal of Arthroplasty 20:59-65. DOI: 10.1016/j.arth.2004.10.010. 
509

510

Li G, Lopez O, Rubash H. 2001. Variability of a three-dimensional finite element model constructed using magnetic resonance images of a knee for joint contact stress analysis. Journal of Biomechanical Engineering-Transactions of the Asme 123:341-346. DOI: Doi 10.1115/1.1385841.

Lohmander LS, Englund PM, Dahl LL, Roos EM. 2007. The long-term consequence of anterior cruciate ligament and meniscus injuries: osteoarthritis. The American Journal of Sports Medicine 35:1756-1769. DOI: 10.1177/0363546507307396.

Manninen P, Riihimäki H, Heliövaara M, Mäkelä P. 1996. Overweight, gender and knee osteoarthritis. International Journal of Obesity and Related Metabolic Disorders: Journal of the International Association for the Study of Obesity 20:595-597.

Momersteeg TJ, Blankevoort L, Huiskes R, Kooloos JG, Kauer JM, Hendriks JC. 1995. The effect of variable relative insertion orientation of human knee bone-ligament-bone complexes on the tensile stiffness. Journal of Biomechanics 28:745-752. DOI: 10.1016/0021-9290(94)00121-j.

Moon DK, Woo SLY, Takakura Y, Gabriel MT, Abramowitch SD. 2006. The effects of refreezing on the viscoelastic and tensile properties of ligaments. Journal of Biomechanics 39:1153-1157. DOI: 10.1016/j.jbiomech.2005.02.012.

Moore A, Burris DL. 2015. Tribological and material properties for cartilage of and throughout the bovine stifle: support for the altered joint kinematics hypothesis of osteoarthritis. Osteoarthritis and cartilage / OARS, Osteoarthritis Research Society 23:161-169. DOI: 10.1016/j.joca.2014.09.021.

Morrison JB. 1970. The mechanics of the knee joint in relation to normal walking. Journal of Biomechanics 3:51-61. DOI: 10.1016/0021-9290(70)90050-3.

Mullaji AB, Marawar SV, Simha M, Jindal G. 2008. Cruciate ligaments in arthritic knees: a histologic study with radiologic correlation. The Journal of Arthroplasty 23:567-572. DOI: 10.1016/j.arth.2007.05.024. 
535 Nawata K, Enokida M, Yamasaki D, Minamizaki T, Hagino H, Morio Y, Teshima R. 2001. Tensile properties of rat anterior cruciate ligament in collagen induced arthritis. Annals of

Nelissen RG, Hogendoorn PC. 2001. Retain or sacrifice the posterior cruciate ligament in total the Rheumatic Diseases 60:395-398. DOI: 10.1136/ard.60.4.395.

Ng GYF. 2002. Ligament Injury and Repair: Current Concepts. Hong Kong Physiotherapy Journal 20:22-29. DOI: 10.1016/S1013-7025(09)70028-4.

544 Nigg BM, Herzog W. 2007. Biomechanics of the Musculo-skeletal System. West Sussex: Wiley.

545 Noyes FR, Grood ES. 1976. The strength of the anterior cruciate ligament in humans and Rhesus monkeys. The Journal of Bone and Joint Surgery 58:1074-1082.

547 Patel RM, Castile RM, Jenkins MJ, Lake SP, Brophy RH. 2021. Microstructural and Mechanical Properties of the Anterolateral Ligament of the Knee. The American Journal of Sports

Pelletier J-P, Raynauld J-P, Berthiaume M-J, Abram F, Choquette D, Haraoui B, Beary JF, Cline GA, Meyer JM, Martel-Pelletier J. 2007. Risk factors associated with the loss of cartilage

555 Peters AE, Akhtar R, Comerford EJ, Bates KT. 2018a. Tissue material properties and volume on weight-bearing areas in knee osteoarthritis patients assessed by quantitative magnetic resonance imaging: a longitudinal study. Arthritis Research \& Therapy 9:R74. computational modelling of the human tibiofemoral joint: a critical review. PeerJ 6:e4298. DOI: $10.7717 /$ peerj.4298.

Peters AE, Akhtar R, Comerford EJ, Bates KT. 2018b. The effect of ageing and osteoarthritis on the mechanical properties of cartilage and bone in the human knee joint. Scientific Reports 8:5931. DOI: 10.1038/s41598-018-24258-6. 
Peters AE, Comerford EJ, Macaulay S, Bates KT, Akhtar R. 2017. Micromechanical properties of canine femoral articular cartilage following multiple freeze-thaw cycles. Journal of the mechanical behavior of biomedical materials 71:114-121. DOI: 10.1016/j.jmbbm.2017.03.006.

Poole AR. 2012. Osteoarthritis as a whole joint disease. HSS journal: the musculoskeletal journal of Hospital for Special Surgery 8:4-6. DOI: 10.1007/s11420-011-9248-6.

Race A, Amis AA. 1994. The mechanical properties of the two bundles of the human posterior

Ratcliffe A, Butler DL, Dyment NA, Cagle PJ, Proctor CS, Ratcliffe SS, Flatow EL. 2015. Engineering 43:819-831. DOI: 10.1007/s10439-015-1263-1.

Readioff R, Geraghty B, Comerford E, Elsheikh A. 2020a. A full-field 3D digital image correlation and modelling technique to characterise anterior cruciate ligament mechanics ex vivo. Acta Biomaterialia 113:417-428. DOI: 10.1016/j.actbio.2020.07.003. canine cranial cruciate ligament complex at slow strain rates. PeerJ 8:e10635. DOI: 10.7717/peerj.10635.

Robinson JR, Bull AMJ, Amis AA. 2005. Structural properties of the medial collateral ligament complex of the human knee. Journal of Biomechanics 38:1067-1074. DOI: 10.1016/j.jbiomech.2004.05.034.

Rousseau JC, Garnero P. 2012. Biological markers in osteoarthritis. Bone 51:265-277. DOI: 10.1016/j.bone.2012.04.001.

Salem GJ, Wang MY, Young JT, Marion M, Greendale GA. 2000. Knee strength and lower- and higher-intensity functional performance in older adults. Medicine and Science in Sports and Exercise 32:1679-1684. DOI: 10.1097/00005768-200010000-00003. 
587

588

589

590

591

592

593

594

595

596

597

598

599

600

601

602

603

604

605

606

607

608

609

610

611

612

Schneider CA, Rasband WS, Eliceiri KW. 2012. NIH Image to ImageJ: 25 years of image analysis. Nature Methods 9:671-675. DOI: 10.1038/nmeth.2089.

Sharma A, Leszko F, Komistek RD, Scuderi GR, Cates HE, Liu F. 2008. In vivo patellofemoral forces in high flexion total knee arthroplasty. Journal of Biomechanics 41:642-648. DOI: 10.1016/j.jbiomech.2007.09.027.

Shelburne KB, Pandy MG, Anderson FC, Torry MR. 2004. Pattern of anterior cruciate ligament force in normal walking. Journal of Biomechanics 37:797-805.

Simon D, Mascarenhas R, Saltzman BM, Rollins M, Bach BR, MacDonald P. 2015. The Relationship between Anterior Cruciate Ligament Injury and Osteoarthritis of the Knee. Advances in Orthopedics 2015:e928301. DOI: 10.1155/2015/928301.

Smeets K, Slane J, Scheys L, Claes S, Bellemans J. 2017. Mechanical Analysis of ExtraArticular Knee Ligaments. Part One: Native knee ligaments. The Knee 24:949-956. DOI: 10.1016/j.knee.2017.07.013.

Stubbs G, Dahlstrom J, Papantoniou P, Cherian M. 2005. Correlation between macroscopic changes of arthrosis and the posterior cruciate ligament histology in the osteoarthritic knee. ANZ journal of surgery 75:1036-1040. DOI: 10.1111/j.1445-2197.2005.03610.x.

Tipton CM, Matthes RD, Maynard JA, Carey RA. 1975. The influence of physical activity on ligaments and tendons. Medicine and Science in Sports 7:165-175.

Trent PS, Walker PS, Wolf B. 1976. Ligament length patterns, strength, and rotational axes of the knee joint. Clinical Orthopaedics and Related Research:263-270.

Wang Y, Fan Y, Zhang M. 2014. Comparison of stress on knee cartilage during kneeling and standing using finite element models. Medical Engineering \& Physics 36:439-447. DOI: 10.1016/j.medengphy.2014.01.004.

Watanabe A, Kanamori A, Ikeda K, Ochiai N. 2011. Histological evaluation and comparison of the anteromedial and posterolateral bundle of the human anterior cruciate ligament of the osteoarthritic knee joint. The Knee 18:47-50. DOI: 10.1016/j.knee.2009.12.009. 
613 Woo SL-Y, Abramowitch SD, Kilger R, Liang R. 2006. Biomechanics of knee ligaments: injury,

614 healing, and repair. Journal of Biomechanics 39:1-20. DOI:

$615 \quad$ 10.1016/j.jbiomech.2004.10.025.

616 Woo SLY, Hollis JM, Adams DJ, Lyon RM, Takai S. 1991. Tensile properties of the human

617 femur-anterior cruciate ligament-tibia complex. The effects of specimen age and

618 orientation. The American Journal of Sports Medicine 19:217-225.

619 Woo SLY, Orlando CA, Camp JF, Akeson WH. 1986. Effects of postmortem storage by freezing

620 on ligament tensile behavior. Journal of Biomechanics 19:399-404. DOI: Doi

$621 \quad 10.1016 / 0021-9290(86) 90016-3$.

622 Yang G, Rothrauff BB, Tuan RS. 2013. Tendon and ligament regeneration and repair: clinical

623 relevance and developmental paradigm. Birth Defects Research. Part C, Embryo Today:

624 Reviews 99:203-222. DOI: 10.1002/bdrc.21041. 


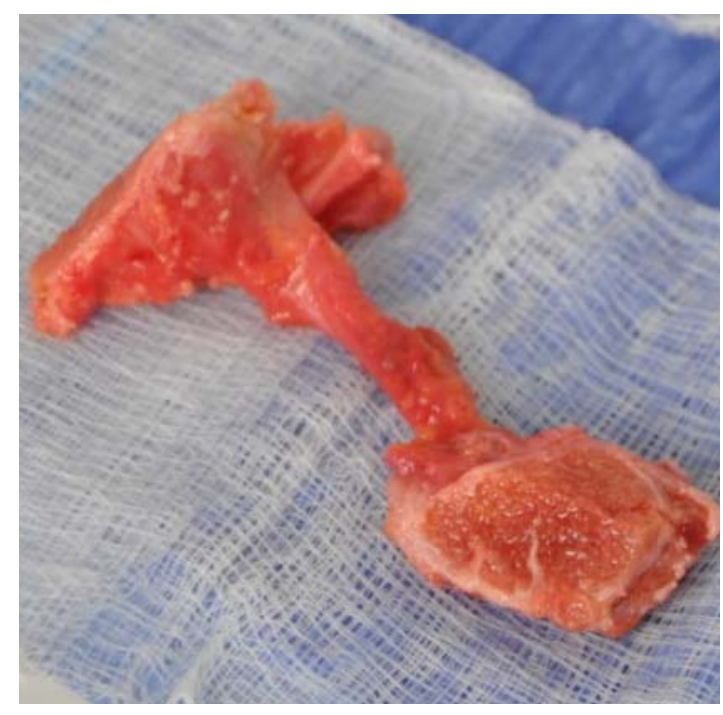

(A)

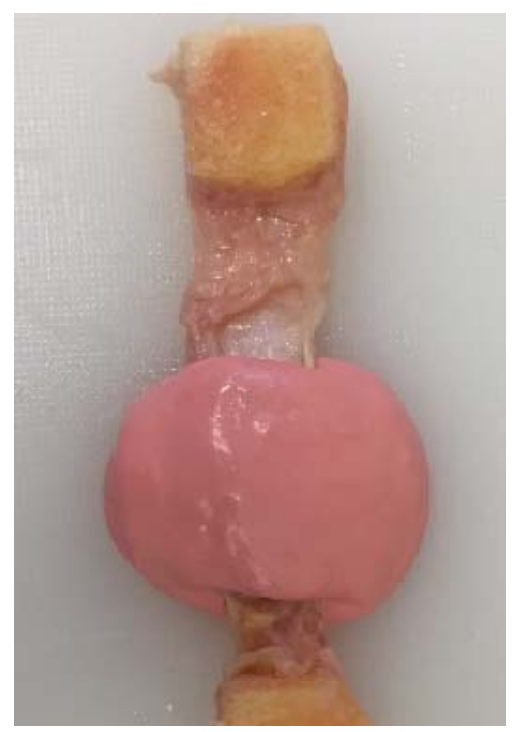

(B)

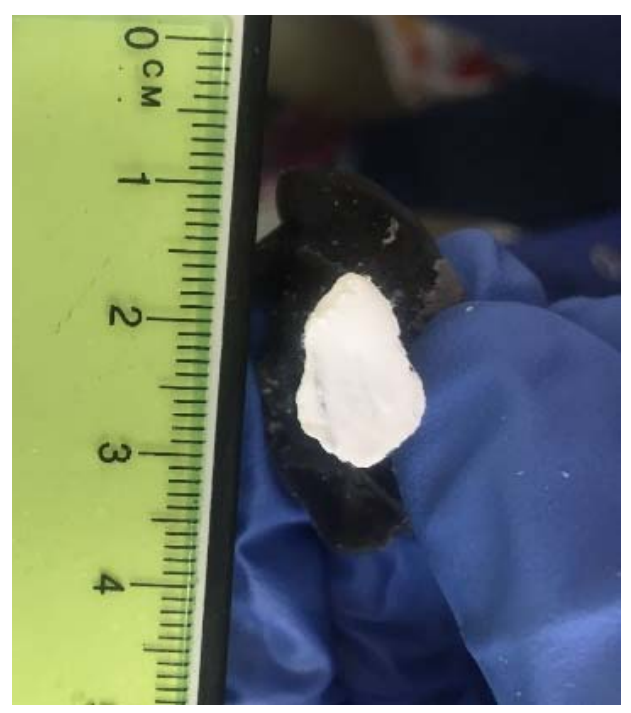

(C)

Fig. 1. Bone-ligament-bone preparation and method for measuring the middle cross-sectional area of knee joint ligament specimens. (A) Bone-ligament-bone specimen. (B) Ligament encased in impression material. (C) Polymethyl-methacrylate cast of a ligament photographed for crosssectional area measurement. 


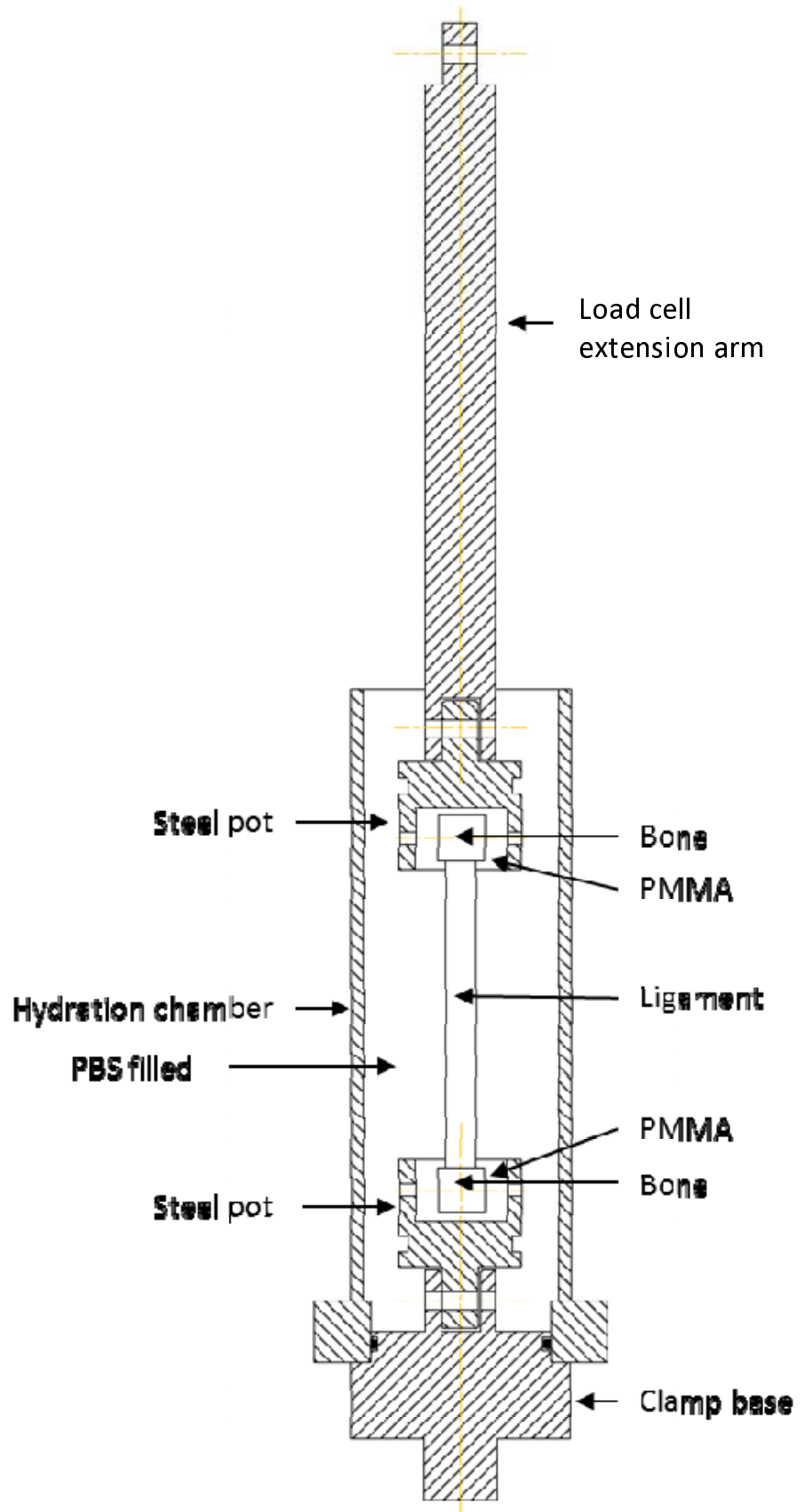

Fig. 2. Schematic illustration of the custom-made rig for tensile testing of human knee joint ligaments. The bone ends of the ligament were secured by potting them into a polymethylmethacrylate (PMMA) holder. Ligaments were encased into a watertight chamber filled with phosphate buffer saline (PBS) to maintain tissue hydration during mechanical tests. 


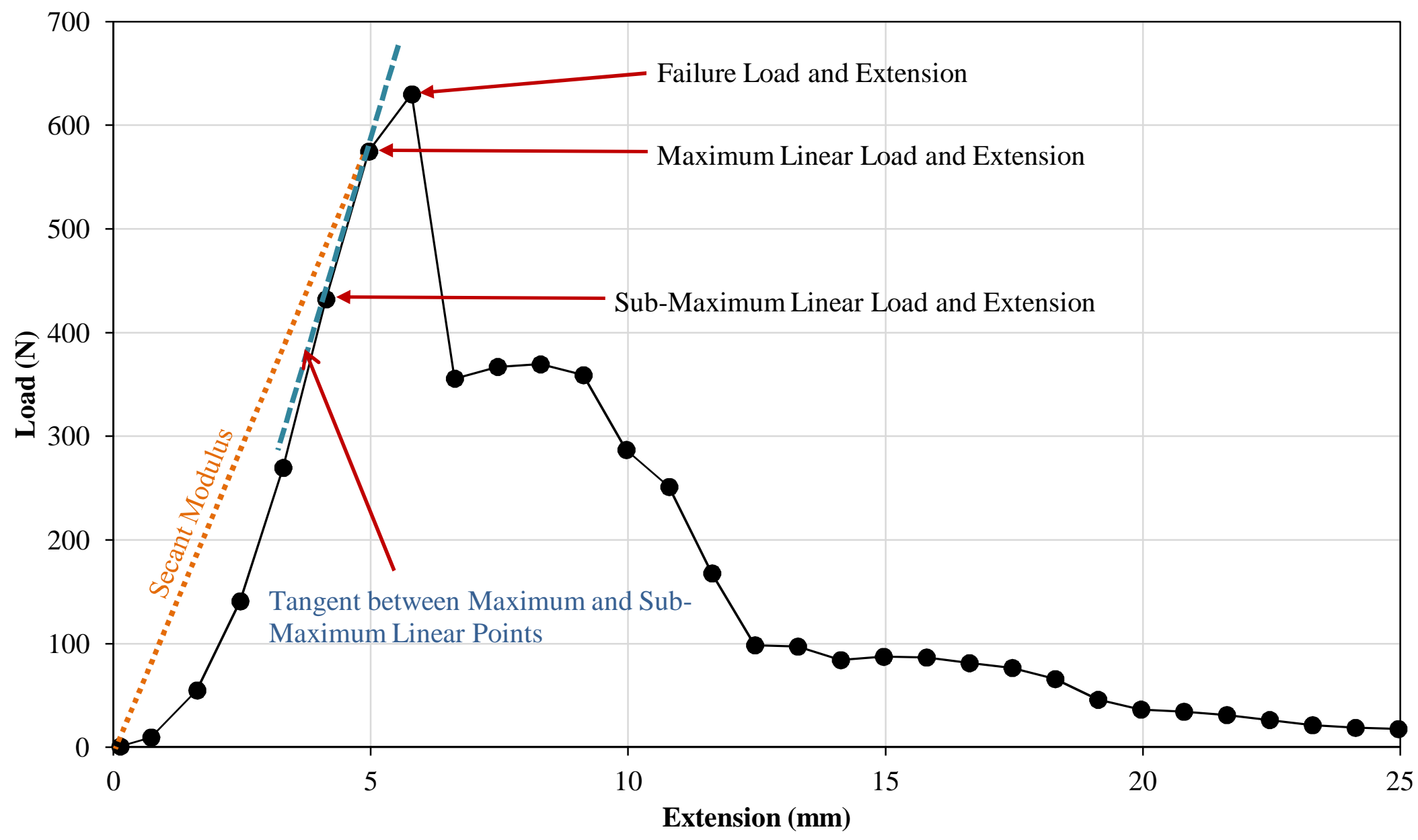

Fig. 3. Example of a load-extension curve, showing failure load and elongation point, maximum and sub-maximum linear loads in Newtons (N), and extensions in millimetres $(\mathrm{mm})$ human knee joint ligaments. The figure also highlights the tangent modulus between maximum and sub-maximum linear points and the secant modulus. 


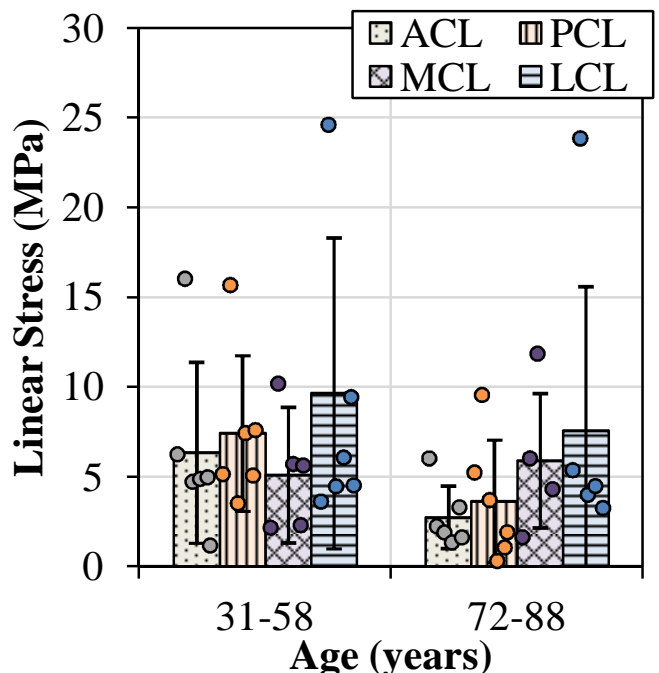

(A)

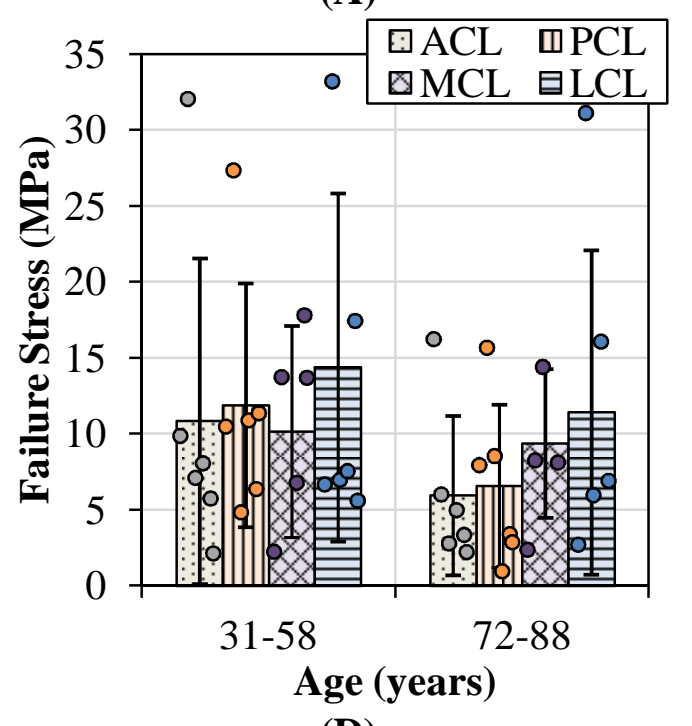

(D)

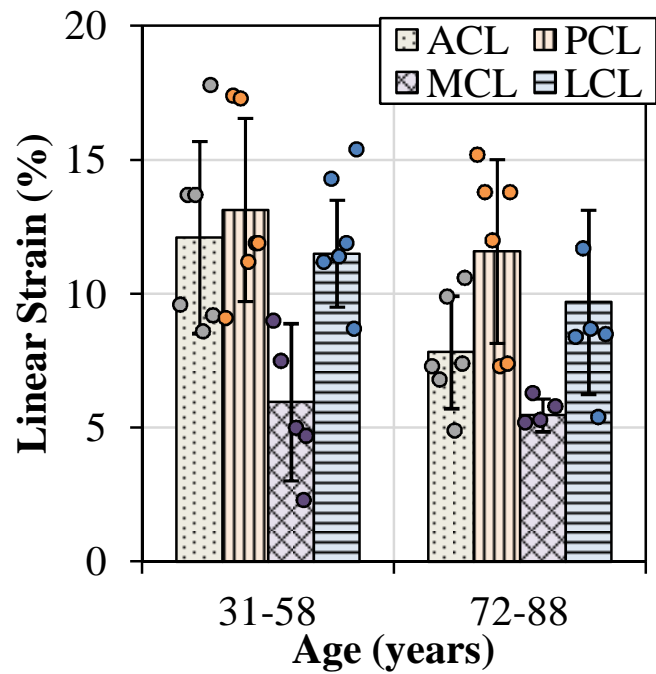

(B)

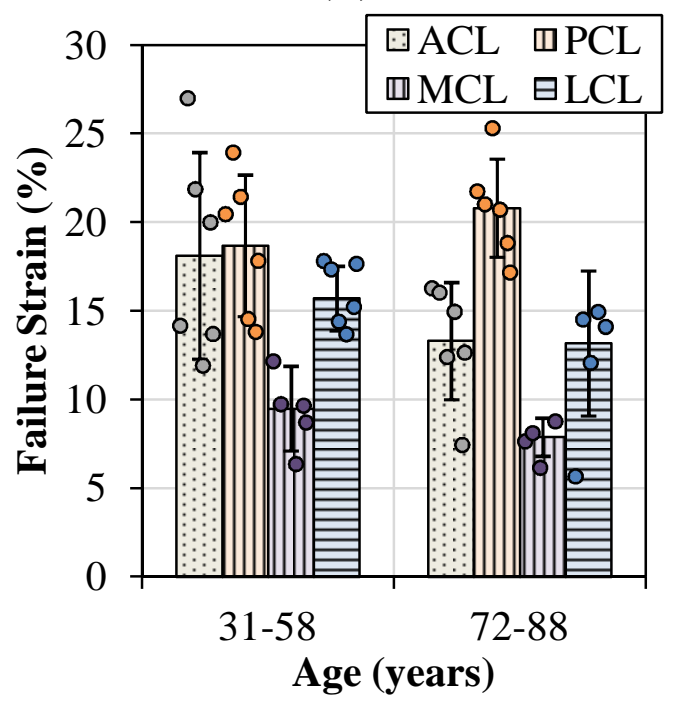

(E)

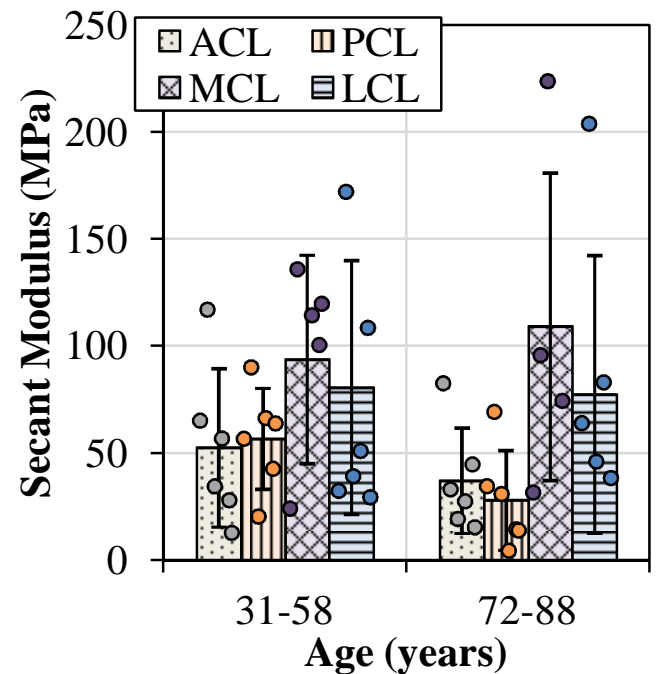

(C)

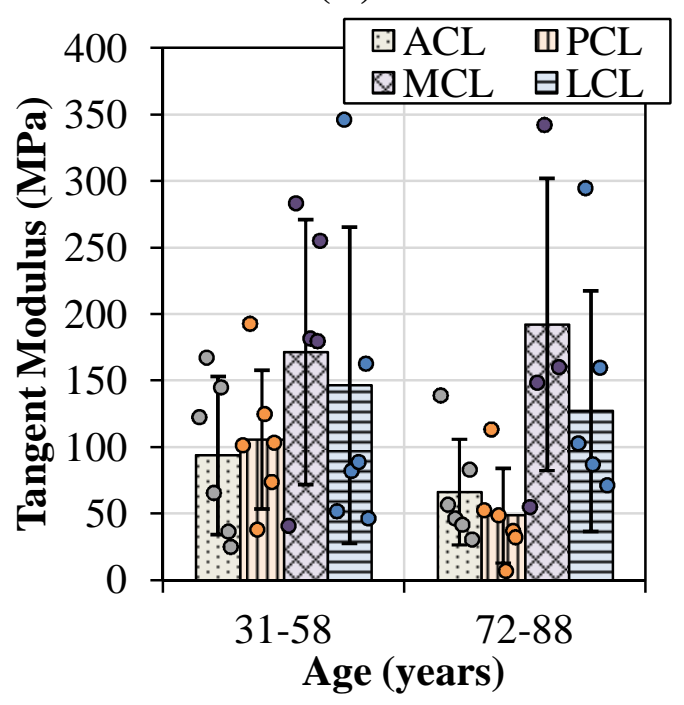

(F) 


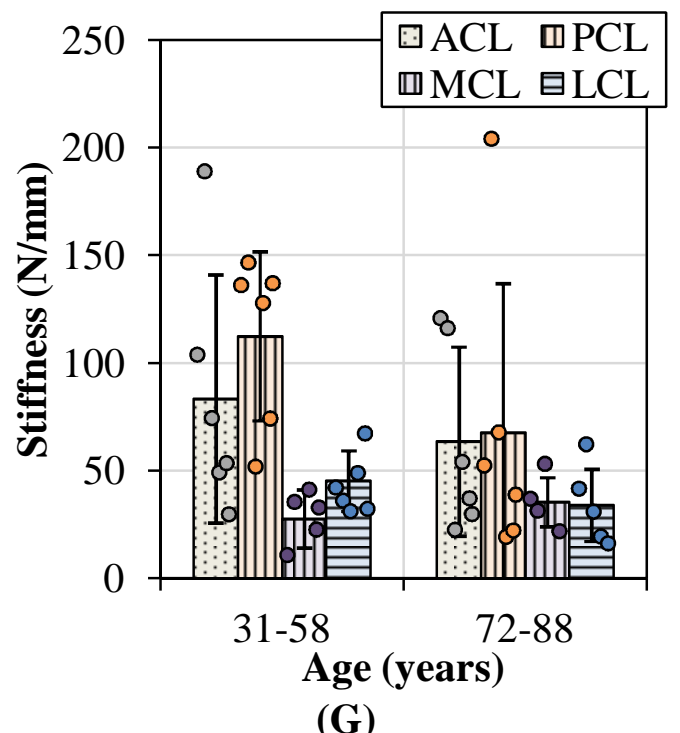

Fig. 4. Tensile parameters for the anterior (ACL) and posterior (PCL) cruciate ligaments, and lateral (LCL) and medial (MCL) collateral ligaments across two age groups (31-58 and 72-88 years old). Error bars represent standard deviation. (A) Linear stress and (B) linear strain were utilized to determine (C) secant modulus. (D) and (E) demonstrates the maximum stresses and strains that resulted in ligament failures. (F) This figure shows tangent modulus of the ligaments between the two age groups at the maximum linear region of load-extension curves. (G) This figure documents the change in stiffness of the ligaments with age. 
$\square$ ACL $\square$ PCL $\square$ MCL $\square$ LCL

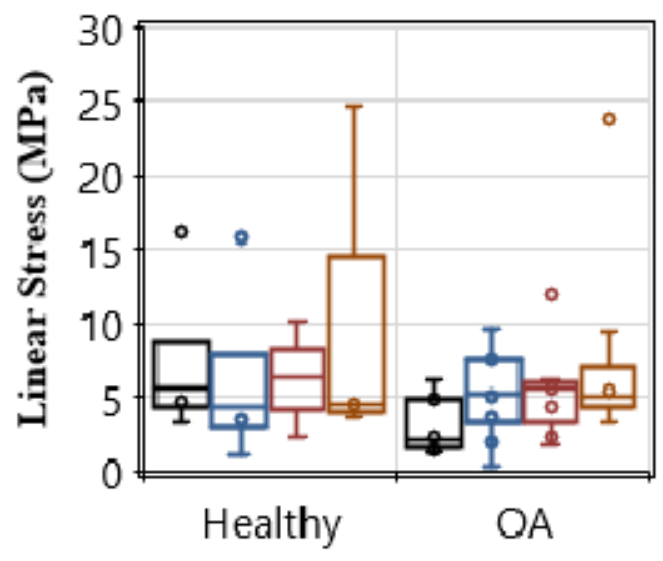

(A)

$\square$ ACL $\square$ PCL $\square$ MCL $\square$ LCL

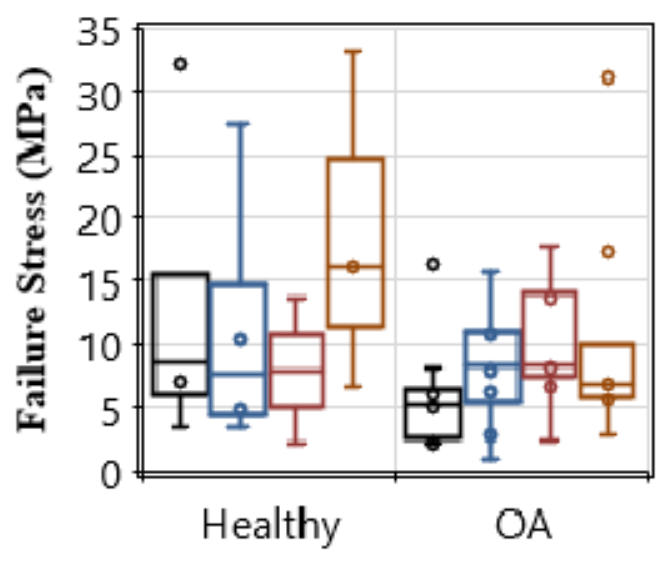

(D) $\square$ ACL $\square$ PCL $\square$ MCL $\square$ LCL

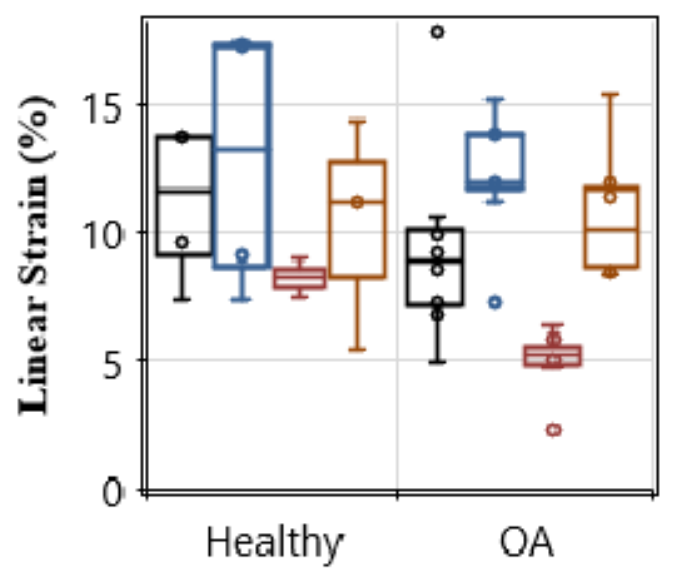

(B)

$\square$ ACL $\square$ PCL $\square$ MCL $\square$ LCL

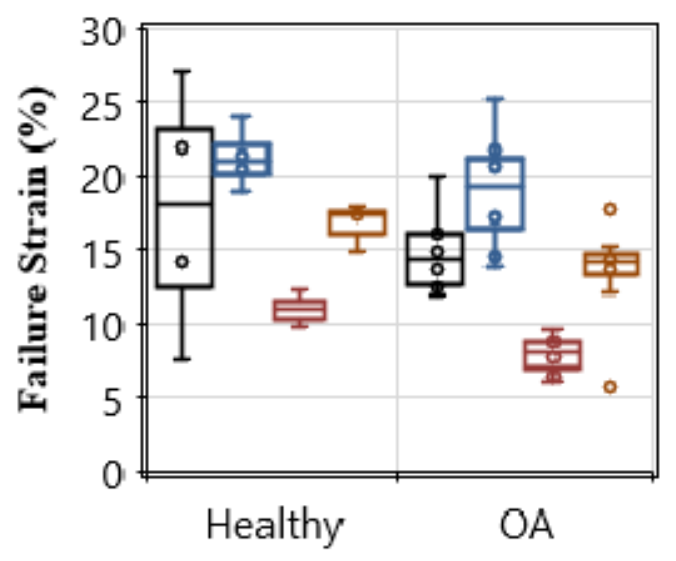

(E) $\square$ ACL $\square \mathrm{PCL} \square \mathrm{MCL} \square \mathrm{LCL}$

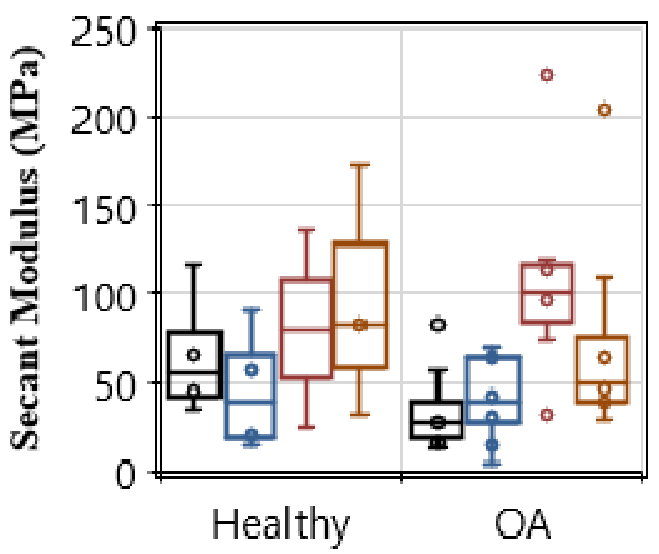

(C)

$\square$ ACL $\square$ PCL $\square$ MCL $\square$ LCL

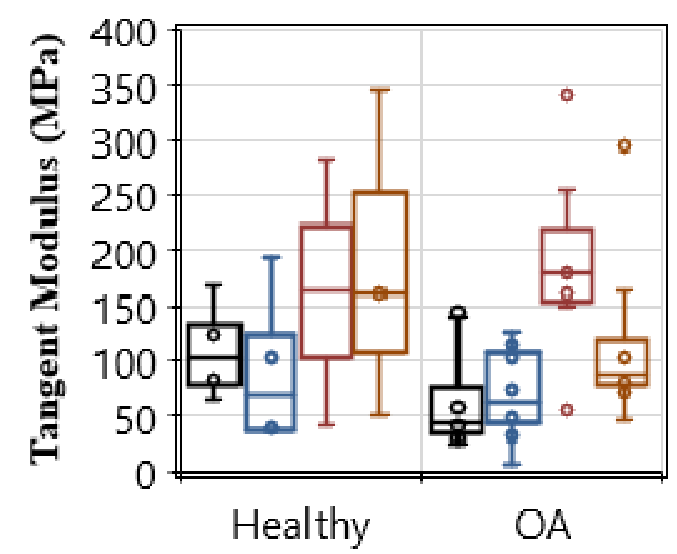

(F) 


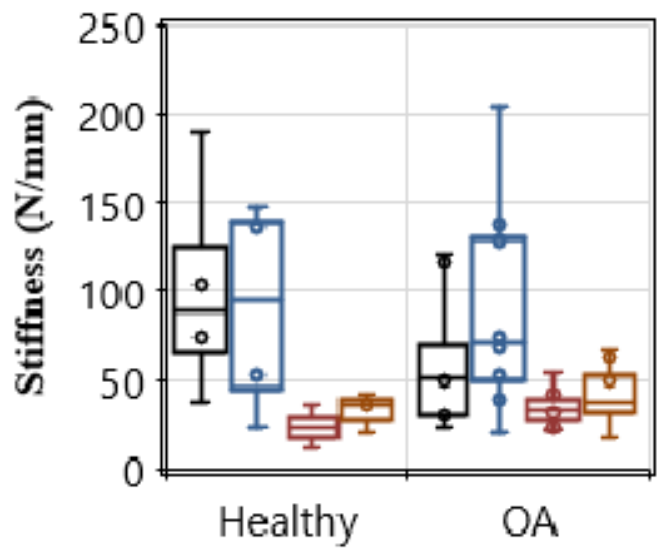

(G)

Fig. 5. Comparisons of tensile properties of the anterior (ACL) and posterior (PCL) cruciate ligaments, and lateral (LCL) and medial (MCL) collateral ligaments between healthy and osteoarthritic (OA) groups. Healthy groups were defined by International Cartilage Repair Society (ICRS) grade 0 and osteoarthritic (OA) was defined by ICRS grade 1-4. (A) Linear stress and (B) linear strain were utilized to determine (C) secant modulus. (D) and (E) demonstrates the maximum stresses and strains that resulted in ligament failures. (F) This figure shows tangent modulus of the ligaments between the healthy and OA groups at the maximum linear region of load-extension curves. (G) This figure documents ligament stiffness values across ligaments and between the healthy and OA groups. 
Table 1: Anterior (ACL) and posterior (PCL) cruciate ligaments, medial (MCL) and lateral (LCL) collateral ligaments material property data for all cadavers. ABREVIATIONS: OA ICRS, osteoarthritis International Cartilage Repair Society; $L_{0}$, original length of the ligament; $C S A$, cross-sectional area; $F$, force or load; $\sigma$, stress; $\varepsilon$, strain at the maximum point of the linear region (max linear) and failure (failure) point of the load-extension curve;

$\boldsymbol{E}_{\text {secant }}$, secant modulus; $\boldsymbol{E}_{\boldsymbol{t a n}}$, tangent modulus; $k$, stiffness; I, insertion; MS, mid-substance; BA, bony avulsion.

\begin{tabular}{|c|c|c|c|c|c|c|c|c|c|c|c|c|c|c|c|c|c|}
\hline 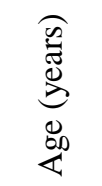 & $\stackrel{x}{\infty}$ & 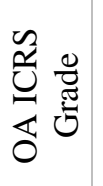 & 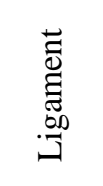 & $\begin{array}{l}\hat{\Xi} \\
\text { g } \\
\end{array}$ & 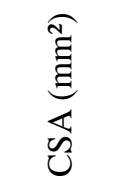 & 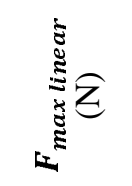 & 胥 & 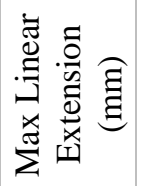 & 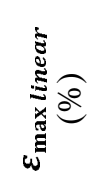 & 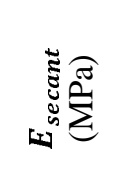 & 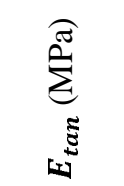 & 於 & 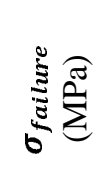 & 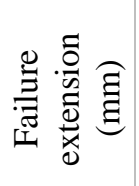 & 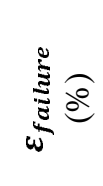 & $\underbrace{\stackrel{\Xi}{z}}_{\approx}$ & 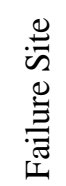 \\
\hline \multirow{4}{*}{31} & \multirow{4}{*}{ Female } & \multirow{4}{*}{0} & ACL & 40 & 63.80 & 574.78 & 9.01 & 4.96 & 12.40 & 29.06 & 171.04 & 629.94 & 9.87 & 5.79 & 14.48 & 46.36 & I \\
\hline & & & PCL & 36 & 86.53 & 624.66 & 7.22 & 4.34 & 12.05 & 21.57 & 238.72 & 930.27 & 10.75 & 8.50 & 23.62 & 51.84 & MS \\
\hline & & & LCL & 62 & 17.10 & 477.63 & 27.93 & 10.98 & 17.71 & 97.79 & 95.80 & 545.90 & 31.92 & 11.81 & 19.05 & 26.98 & MS \\
\hline & & & MCL & 103 & 24.51 & 332.35 & 13.56 & 6.74 & 6.54 & 213.56 & 85.96 & 438.48 & 17.89 & 8.40 & 8.16 & 50.82 & MS \\
\hline \multirow{4}{*}{37} & \multirow{4}{*}{ Female* } & \multirow{4}{*}{0} & $\mathrm{ACL}$ & 30 & 48.46 & 1345.42 & 27.76 & 6.75 & 22.50 & 37.03 & 239.08 & 1554.16 & 32.07 & 8.42 & 28.05 & 59.81 & BA \\
\hline & & & PCL & 30 & 48.82 & 1107.59 & 22.69 & 9.72 & 32.41 & 21.00 & 293.42 & 1336.49 & 27.37 & 10.56 & 35.19 & 34.17 & BA \\
\hline & & & LCL & 55 & 71.75 & 280.88 & 3.91 & 7.89 & 14.34 & 15.02 & 70.23 & 479.73 & 6.69 & 11.22 & 20.40 & 19.59 & I \\
\hline & & & MCL & 40 & 18.19 & 33.21 & 1.83 & 4.06 & 10.15 & 7.19 & 14.32 & 47.93 & 2.63 & 4.90 & 12.24 & 3.27 & MS \\
\hline \multirow{4}{*}{43} & \multirow{4}{*}{ Female } & \multirow{4}{*}{0} & $\mathrm{ACL}$ & 32 & 71.27 & 467.52 & 6.56 & 5.78 & 18.08 & 11.61 & 126.42 & 576.94 & 8.09 & 9.95 & 31.10 & 25.86 & MS \\
\hline & & & PCL & 30 & 76.53 & 369.20 & 4.82 & 6.83 & 22.78 & 6.35 & 73.99 & 1220.92 & 15.95 & 15.17 & 50.56 & 16.21 & MS \\
\hline & & & LCL & 61 & 12.83 & 81.49 & 6.35 & 4.39 & 7.19 & 53.89 & 34.31 & 426.52 & 33.25 & 11.05 & 18.12 & 11.33 & MS \\
\hline & & & MCL & 108 & 28.29 & 343.16 & 12.13 & 11.16 & 10.34 & 126.76 & 75.41 & 727.51 & 25.72 & 19.50 & 18.05 & 33.20 & MS \\
\hline \multirow{4}{*}{49} & \multirow{4}{*}{ Male } & \multirow{4}{*}{1} & $\mathrm{ACL}$ & 40 & 34.68 & 229.22 & 6.61 & 6.87 & 17.17 & 15.40 & 120.79 & 340.82 & 9.83 & 9.37 & 23.42 & 13.35 & MS \\
\hline & & & PCL & 44 & 84.79 & 777.84 & 9.17 & 5.96 & 13.55 & 29.79 & 229.97 & 963.21 & 11.36 & 9.29 & 21.12 & 57.41 & MS \\
\hline & & & LCL & 52 & 39.91 & 279.40 & 7.00 & 15.88 & 30.55 & 11.92 & 67.32 & 438.52 & 10.99 & 21.72 & 41.76 & 9.15 & MS \\
\hline & & & MCL & 101 & 22.37 & 137.53 & 6.15 & 10.92 & 10.81 & 57.44 & 35.88 & 552.09 & 24.68 & 17.59 & 17.41 & 12.72 & MS \\
\hline \multirow{4}{*}{51} & \multirow{4}{*}{ Male } & \multirow{4}{*}{1} & ACL & 28 & 53.64 & 249.76 & 4.66 & 4.89 & 17.48 & 7.46 & 53.79 & 504.97 & 9.41 & 12.39 & 44.27 & 14.29 & MS \\
\hline & & & PCL & 34 & 59.24 & 378.24 & 6.38 & 4.89 & 14.38 & 15.10 & 120.23 & 1052.61 & 17.77 & 15.72 & 46.24 & 26.31 & I \\
\hline & & & LCL & 47 & 45.15 & 341.77 & 7.57 & 7.04 & 14.97 & 23.77 & 81.27 & 419.25 & 9.29 & 15.37 & 32.70 & 22.83 & I \\
\hline & & & MCL & 114 & 41.18 & 279.31 & 6.78 & 7.32 & 6.42 & 120.38 & 61.30 & 354.33 & 8.61 & 13.99 & 12.27 & 43.48 & MS \\
\hline \multirow{4}{*}{58} & \multirow{4}{*}{ Male } & \multirow{4}{*}{2} & ACL & 41 & 95.79 & 169.90 & 1.77 & 6.97 & 17.00 & 4.28 & 55.47 & 664.31 & 6.93 & 14.47 & 35.29 & 10.00 & MS \\
\hline & & & PCL & 46 & 98.67 & 980.12 & 9.93 & 6.89 & 14.99 & 30.49 & 220.75 & 1380.78 & 13.99 & 10.23 & 22.23 & 65.41 & I \\
\hline & & & LCL & 58 & 36.03 & 388.10 & 10.77 & 5.88 & 10.14 & 61.60 & 103.30 & 629.39 & 17.47 & 9.22 & 15.89 & 38.27 & MS \\
\hline & & & MCL & 127 & 28.80 & 150.06 & 5.21 & 7.85 & 6.18 & 107.01 & 30.76 & 514.05 & 17.85 & 14.52 & 11.43 & 24.27 & MS \\
\hline \multirow{4}{*}{$72(1)$} & \multirow{4}{*}{ Male } & \multirow{4}{*}{3} & ACL & 34 & 49.75 & 569.38 & 11.44 & 3.96 & 11.66 & 33.39 & 197.08 & 808.34 & 16.25 & 5.63 & 16.56 & 48.85 & MS \\
\hline & & & PCL & 41 & 62.51 & 344.93 & 5.52 & 7.67 & 18.71 & 12.09 & 79.10 & 524.83 & 8.40 & 11.84 & 28.88 & 18.43 & BA \\
\hline & & & LCL & 60 & 66.07 & 251.52 & 3.81 & 9.87 & 16.46 & 13.88 & 51.08 & 379.68 & 5.75 & 15.71 & 26.18 & 15.28 & MS \\
\hline & & & MCL & 121 & 33.41 & 235.88 & 7.06 & 8.33 & 6.88 & 124.16 & 71.24 & 458.47 & 13.72 & 12.49 & 10.32 & 34.28 & I \\
\hline \multirow{4}{*}{$72(2)$} & \multirow{4}{*}{ Male } & & ACL & 29 & 101.84 & 265.33 & 2.61 & 2.35 & 8.10 & 9.33 & 189.12 & 613.77 & 6.03 & 4.85 & 16.72 & 32.76 & I \\
\hline & & 3 & PCL & 31 & 91.34 & 1059.28 & 11.60 & 5.03 & 16.23 & 22.15 & 321.15 & 1432.70 & 15.69 & 6.70 & 21.60 & 65.28 & MS \\
\hline & & & LCL & 68 & 44.46 & 282.10 & 6.35 & 7.18 & 10.55 & 40.89 & 66.36 & 352.48 & 7.93 & 11.34 & 16.68 & 26.73 & MS \\
\hline & & & MCL & 110 & 58.68 & 120.41 & 2.05 & 3.64 & 3.31 & 68.15 & 62.58 & 227.10 & 3.87 & 13.64 & 12.40 & 36.35 & MS \\
\hline 79 & Male & 2 & ACL & 32 & 37.78 & 145.15 & 3.84 & 7.43 & 23.21 & 5.30 & 46.39 & 187.78 & 4.97 & 10.76 & 33.63 & 6.25 & I \\
\hline
\end{tabular}




\begin{tabular}{|c|c|c|c|c|c|c|c|c|c|c|c|c|c|c|c|c|c|}
\hline & & & PCL & 32 & 70.34 & 356.25 & 5.06 & 5.61 & 17.54 & 9.24 & 100.22 & 642.60 & 9.14 & 12.28 & 38.37 & 20.31 & MS \\
\hline & & & LCL & 62 & 18.98 & 532.16 & 28.03 & 8.81 & 14.21 & 122.29 & 87.79 & 628.01 & 33.08 & 12.15 & 19.59 & 37.44 & I \\
\hline & & & MCL & 120 & 39.57 & 264.96 & 6.70 & 17.86 & 14.89 & 53.98 & 51.74 & 326.72 & 8.26 & 19.53 & 16.27 & 17.80 & I \\
\hline \multirow{4}{*}{80} & \multirow{4}{*}{ Male } & \multirow{4}{*}{4} & ACL & 38 & 74.89 & 139.35 & 1.86 & 5.67 & 14.91 & 4.74 & 77.25 & 373.94 & 4.99 & 9.00 & 23.68 & 9.35 & MS \\
\hline & & & PCL & 35 & 154.25 & 65.96 & 0.43 & 4.89 & 13.98 & 1.07 & 29.79 & 261.57 & 1.70 & 15.73 & 44.94 & 4.72 & I \\
\hline & & & LCL & 74 & 50.01 & 250.44 & 5.01 & 11.65 & 15.74 & 23.54 & 59.90 & 445.35 & 8.91 & 21.65 & 29.26 & 15.91 & BA \\
\hline & & & MCL & 116 & 27.62 & 399.01 & 14.45 & 7.68 & 6.62 & 253.25 & 73.99 & 492.60 & 17.84 & 12.68 & 10.93 & 60.29 & MS \\
\hline \multirow{3}{*}{86} & \multirow{3}{*}{ Female** } & \multirow{3}{*}{1} & ACL & 30 & 24.98 & 84.17 & 3.37 & 2.57 & 8.58 & 11.78 & 58.95 & 134.33 & 5.38 & 5.91 & 19.69 & 9.81 & I \\
\hline & & & PCL & 43 & 66.54 & 67.81 & 1.02 & 4.68 & 10.89 & 4.02 & 40.68 & 281.04 & 4.22 & 13.85 & 32.21 & 6.23 & I \\
\hline & & & LCL & 60 & 14.17 & 89.69 & 6.33 & 6.91 & 11.52 & 32.98 & 33.56 & 263.26 & 18.58 & 13.58 & 22.63 & 7.79 & MS \\
\hline \multirow{4}{*}{88} & \multirow{4}{*}{ Male } & \multirow{4}{*}{3} & ACL & 33 & 64.32 & 144.40 & 2.25 & 5.18 & 15.68 & 4.72 & 58.76 & 277.47 & 4.31 & 9.34 & 28.31 & 9.21 & I \\
\hline & & & PCL & 34 & 95.25 & 212.68 & 2.23 & 6.33 & 18.60 & 4.08 & 91.30 & 414.07 & 4.35 & 9.66 & 28.41 & 11.43 & I \\
\hline & & & LCL & 58 & 24.78 & 101.97 & 4.12 & 6.44 & 11.10 & 21.50 & 31.79 & 337.54 & 13.62 & 13.94 & 24.03 & 9.19 & I \\
\hline & & & MCL & 120 & 35.55 & 232.72 & 6.55 & 9.55 & 7.96 & 98.69 & 41.48 & 444.18 & 12.49 & 17.05 & 14.21 & 29.24 & MS \\
\hline
\end{tabular}

* Donor had a severely abnormal MCL and was not included in the statistical analysis.

** The MCL from this doner could not be retained for mechanical tests. 